\title{
Uma Experiência de Formação Continuada com Professores de Arte e Matemática no Ensino de Geometria
}

\author{
An Experience of Continuing Education with Art and Mathematics \\ Teachers in Teaching Geometry
}

\author{
Marli Regina dos Santos* \\ Maria Aparecida Viggiani Bicudo**
}

\begin{abstract}
Resumo
Este artigo expõe um trabalho de formação continuada realizado com professores de Matemática e de Arte da Educação Básica, tendo como foco o ensino de geometria por meio das pavimentações do plano. Destacamos a constituição de um núcleo de ideias formado por sentidos percebidos ao enfocarmos essas disciplinas, explicitando que, na origem desse núcleo e na expressão dos significados, evidenciam-se atos como os de observar, intuir, imaginar, criar, projetar, perceber tamanhos e formas. Apresentamos as pavimentações abordadas nos encontros do curso de formação continuada voltado para o ensino de geometria, que possibilitaram o desenvolvimento de atividades com estas distintas disciplinas. Enfocamos os diálogos entre os professores ao empenharem-se para dar conta das atividades propostas, destacando em nossas análises: as perspectivas de olhar dos envolvidos, que se evidenciam nas interações ocorridas; a formação e o pro-jeto docente; e interfaces da Educação Matemática. $\mathrm{O}$ que se mostra nos momentos das vivências ao estar-junto com o outro professor, da mesma e/ou da outra disciplina, indica a constituição da intersubjetividade que possibilita que a interdisciplinaridade aconteça.
\end{abstract}

Palavras-chave: Educação Matemática. Geometria. Pavimentações do Plano. Interdisciplinaridade. Fenomenologia.

\begin{abstract}
This article exposes a work for continuing education of art and mathematics teachers of basic education, focusing on the teaching of geometry through tessellations. We emphasize the constitution of a nucleus of ideas formed by sense perceived when we focus on these disciplines, explaining that, in the origin of this nucleus and expression of meanings, are evident acts as the watch, know, imagine, create and realize sizes and forms. We present the tessellations used in continuing education course, focused on the teaching of geometry, which enabled the development of activities with these different disciplines. We focus on the dialogue among teachers while they engaged in the proposed activities, highlighting our analysis: the perspective of looking; the formation and the project; and interfaces of Mathematics Education. What was shown in the experience together with the teacher, which are of the same or different disciplines, indicates the constitution of intersubjectivity that enables interdisciplinary courses to be given.
\end{abstract}

Keywords: Mathematics Education; Geometry, Interdisciplinarity, Tessellation; Phenomenology.

\footnotetext{
* Doutora em Educação Matemática pela Universidade Estadual Paulista (UNESP) Rio Claro/SP. Professora adjunta da Universidade Federal de Viçosa (UFV), Viçosa/MG. Endereço para correspondência: Avenida PH Rolfs, sn, DMA, Viçosa/MG, CEP 36570-000.E-mail: marli.santos@ufv.br

** Livre-docente pela Faculdade de Ciências Sociais, Letras e Educação da Universidade Estadual Paulista (UNESP), Cidade/SP. Professora titular do Departamento de Matemática da Universidade Estadual Paulista (UNESP), Rio Claro/SP. Endereço para correspondência: Avenida 24 A, n. 1515, Rio Claro/SP, CEP 13506-900. E-mail: mariabicudo@gmail.com
} 


\section{Arte e Matemática no ensino de Geometria}

Ao enfocarmos a Arte e a Matemática, compreendemos que ambas estão entrelaçadas no próprio núcleo que constitui ideias que, no desenrolar das ações cognitivas e teorizantes, expressas em linguagem sustentada na intersubjetividade presente no mundo históricocultural, avançam na produção de conhecimento (HUSSERL, 2012; MERLEAU-PONTY, 1990; BICUDO, 2010). Na origem de sentido desse núcleo e na constituição de significados, deparamo-nos com atos como os de observar, intuir, imaginar, criar, testar, projetar, perceber tamanhos, formas, cores e profundidade, por exemplo.

Esse núcleo comum de sentidos percebidos na constituição do conhecimento da Arte e da Matemática, ao ser trabalhado em atividades de ensino de geometria, pode contribuir com a aprendizagem do tema. Tal constatação embasou a realização de um estudo junto a professores dessas distintas disciplinas (SANTOS, 2006). Afunilando o zoom do olhar nas atividades realizadas no estudo, em um curso de formação continuada, o tema trabalhado, as pavimentações do plano, evidenciou ainda mais a constituição daquelas ideias comuns a um núcleo gerador da produção de conhecimento matemático e artístico.

Muitas pesquisas e textos que enfocam as pavimentações destacam a beleza, a estética e a arte como vinculados ao tema (MURARI, 1999; MARTINS, 2003; ALMEIDA, 2003; GOUVEA, 2005; REIS, 2006; SANTOS, 2006; SANTOS \& BATISTELA, 2013; BUSKE, 2007; NEVES, 2011 etc.). No livro Geometry: an investigative approach (DAFFER \& CLEMENS, 1977), os autores dedicam um capítulo da obra aos padrões de polígonos no plano. O termo tiling ou tessellation nomeia os padrões construídos com figuras poligonais que cobrem completamente o plano, sem "furo" nem "sobreposições" entre eles. Por meio do estudo desses padrões, os autores abordam diversos aspectos geométricos em atividades investigativas, relacionando o tema à arte ornamental e à criação de designs, pinturas e quadros. Eles destacam a arte ao propor a exploração da representação geométrica de desenhos, como ornamentos, tais como faixas, rosetas e mosaicos, para, a partir desses elementos, efetuar estudos sobre os movimentos de translação, reflexão e rotação, propriedades geométricas, relações etc.

As pesquisas e textos apontados, mesmo tendo como foco a Matemática e mais especificamente a geometria, ressaltam as possibilidades educacionais e o caráter artístico das pavimentações. É possível notar convergências quanto à preocupação em trabalhar-se a geometria, em todos os níveis escolares, de modo que ela se torne compreensível e as atividades realizadas prazerosas. Os autores buscam formas mais dinâmicas de abordar o 
assunto e identificam, nas pavimentações, possibilidades de trabalharem-se os conceitos geométricos e, ao mesmo tempo, explorar o senso artístico e a criatividade.

O pensamento artístico, que caracteriza um modo próprio de sentir e ordenar as experiências no mundo, favorece a articulação de distintas disciplinas, auxiliando, por exemplo, no desenvolvimento de estratégias para resolver um problema. A Arte, em suas especificidades, evidencia formas de criação humana e respectivas expressões, as quais também se dão, por exemplo, na Literatura e nas Ciências em geral, inclusive nas Ciências Exatas. No que concerne à Matemática, a Arte, ao exercitar continuamente a imaginação, abre possibilidades para caminhos de resolução de situações problema que podem envolver o raciocínio matemático.

Aranha (1981, p.12) afirma que "a arte é uma possibilidade do ser-no-mundo de desvelar um horizonte de significados, de criar para si um lugar o qual habita". A Matemática também responde a essa necessidade humana de buscar compreensões sobre o mundo e o entorno em que se está.

A afinidade entre a construção dos conceitos geométricos e o desenvolvimento do senso artístico e da criatividade evidencia, sobremaneira, a ligação entre Arte e Matemática. O pensamento geométrico e as ideias artísticas se entrelaçam em um movimento de constituição comum. O ser humano percebe e compreende o mundo e o espaço ao seu redor, espacializando seu entorno, habitando horizontes que se abrem, criando, assim, modos de apresentar sua compreensão (MERLEAU-PONTY, 1990; BICUDO, 2012) sendo a Arte e a geometria formas de manifestação humana de compreensões que se articulam e expõem-se de maneira complexa.

Em sala de aula, a constituição do núcleo de ideias matemática-arte pode ser trabalhada de muitos modos. Em uma pintura, por exemplo, podem ser propostas possibilidades que se abrem para o ensino e para a aprendizagem das ideias geométricas, mediante a experiência de olhar de modo atento, dando-se destaque à visualização do espaço, aos traços de linhas e curvas, bem como às formas que se delineiam, ainda que de modo fugidio. Há um entrelaçamento de sentidos e de significados que se amalgamam, podendo constituir ideias geométricas que dizem do que está sendo compreendido e produzido. Assim, tais ideias se doam em diferentes situações vivenciadas e podem avançar em complexidade de sentidos e significados, de modo a se produzirem conceitos ou tão somente explicitar, ou mesmo anunciar, evidências percebidas. Desse modo, a produção do conhecimento geométrico não se esgota em uma única área: ele é dinâmico e complexo e solicita, mesmo 
nas aulas formais de Matemática, que se dê conta do sentido percebido, que pode apontar para diversas direções e diferentes contextos.

Os conceitos geométricos podem ser considerados em diferentes pontos de vista, pois a geometria pode ser compreendida em muitos aspectos e de muitas perspectivas, não existindo um caminho linear e hierárquico que organize desde os princípios elementares até as abstrações e axiomas. Por isso, um trabalho interdisciplinar revela-se significativo.

Entendendo que a realização de projetos se dá mediante ações que atualizam a potência, compreendida como possibilidades de vir a ser de algo, na conjunção da forma e matéria, tomamos o projeto ensino e aprendizagem de geometria passível de ser atualizado interdisciplinarmente. Para além do olhar que vê conjuntamente Matemática e Arte no ensino do tema por meio das pavimentações do plano e recursos manipuláveis, exporemos um estudo que colocou em evidência a expressão da intersubjetividade mantida no estar junto aos participantes de um curso de formação continuada, com foco na geometria e nessas duas disciplinas (SANTOS, 2006).

A seguir, apresentamos as pavimentações abordadas no estudo, trazendo aspectos da relação Matemática e Arte e, após, análises realizadas em uma abordagem fenomenológica (BICUDO, 2010), buscando contribuir com a discussão ocorrida na ocasião da efetivação do estudo de Santos (2006). Para isso, trazemos alguns diálogos e compreensões relatadas, as quais embasarão as reflexões e encaminhamentos trazidos aqui. Os sujeitos desencadeadores das ações e diálogo são os próprios pesquisadores e os professores participantes. Ao final, focamos as interfaces da Educação Matemática, propondo questões que ainda carecem de estudos que possam trazer novos aspectos para a discussão sobre interdisciplinaridade, ensino e aprendizagem de geometria e a pesquisa multidisciplinar.

\section{As pavimentações do plano e a experiência de formação continuada}

A arte de desenhar pavimentações e padrões é muito antiga. Os mosaicos estavam presentes no artesanato e nos utensílios das civilizações babilônica, grega, chinesa, entre outras, sendo que muitos apresentavam padrões geométricos com simetrias ornamentais, formando desenhos harmoniosos (BARBOSA, 1993). Mas o estudo das propriedades e relações geométricas das pavimentações por polígonos é recente, principalmente em termos de suas potencialidades pedagógicas (DAFFER \& CLEMENS, 1977).

As pavimentações do plano por polígonos consistem no recobrimento de uma região plana sem que haja espaços ou sobreposição entre os polígonos. Nos encontros do curso com 
os professores, três tipos de pavimentações foram estudadas: pavimentações por polígonos regulares e visualização em caleidoscópios; pavimentações por tetraminós; e pavimentações aperiódicas de Penrose. É importante destacar, desde já, que o foco deste artigo é abordar as interações ocorridas nos encontros com os professores de Arte e Matemática. Por isso, o estudo teórico matemático das pavimentações aqui abordadas será omitido e veremos, sucintamente, aspectos de cada uma delas, sem detalhar notações, propriedades ou relações ${ }^{1}$.

\subsection{Pavimentações por polígonos regulares e visualização em caleidoscópio}

As pavimentações por polígonos regulares foram obtidas a partir dos trabalhos de Platão e Arquimedes. São formadas por polígonos regulares de um só tipo ou por uma combinação deles. No estudo de Santos (2006), apenas aquelas que apresentam um único tipo de padrão de repetição foram abordadas (apresentamos algumas na Figura 1). Note que a configuração de polígonos em cada vértice é sempre a mesma.

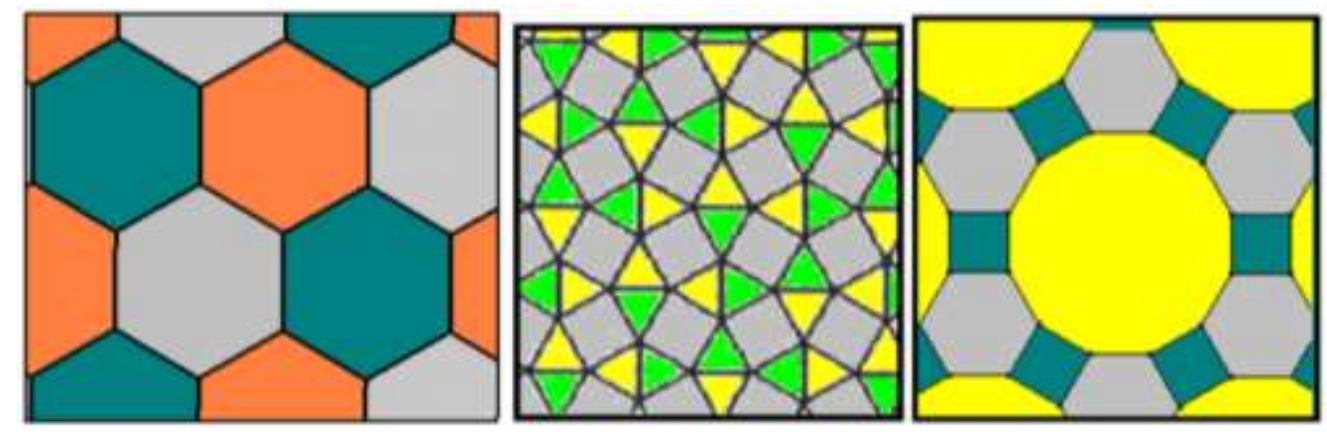

Figura 1 - Algumas pavimentações por polígonos regulares Fonte: (SANTOS, 2006)

Nos encontros com os professores, o tema foi introduzido por meio de um kit constituído por polígonos de E.V.A (Figura 2). O material didático foi um recurso importante para o estudo das propriedades geométricas e permitiu que, em conjunto, os professores intuíssem e testassem suas hipóteses.

\footnotetext{
${ }^{1}$ Mais detalhes das relações e propriedades das pavimentações aqui apresentadas podem ser encontrados em Santos (2006), Murari (1999), Barbosa (1993), entre outros trabalhos indicados neste artigo.
} 


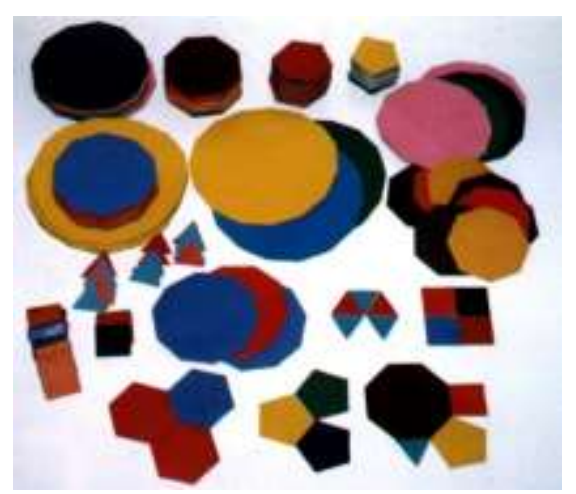

Figura 2 - Kit de polígonos regulares Fonte: (SANTOS, 2006)

Por meio de um roteiro de atividades propostas, eles deveriam investigar e registrar as combinações de polígonos que podiam pavimentar o plano. A partir daí, muitos conceitos e propriedades geométricas foram analisados.

Para complementar o estudo e explorar novos conteúdos geométricos, foram utilizados os caleidoscópios. Trata-se de um conjunto de dois ou mais espelhos planos, articulados entre si, que possibilita a reflexão perfeita de imagens, ou seja, que gera imagens idênticas por meio dos espelhos. Seu nome é originário de três palavras gregas: Kalos (belas), eidos (formas) e skopein (ver).

Para fins educacionais, Murari (1999) recomenda que se trabalhe com o caleidoscópio modificado (Figura 3). Ele é composto por espelhos maiores, o que possibilita o trabalho em grupo e a obtenção de três tipos de caleidoscópios: o equilátero, o isósceles e o escaleno.

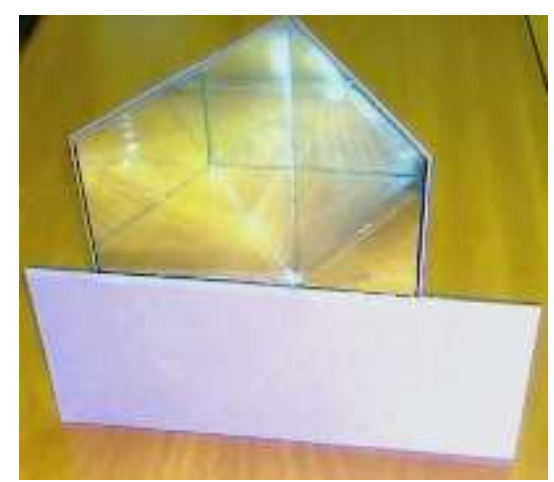

Figura 3 - Caleidoscópio modificado, para uso educacional Fonte: (SANTOS, 2006)

Ao observamos as imagens geradas em espelhos articulados entre si, visualizamos, devido à reflexão de um espelho no outro, espelhos virtuais que parecem refletir as imagens de objetos colocados entre os espelhos. $\mathrm{O}$ visual gerado é muito bonito e atraente.

Os caleidoscópios permitem a visualização de pavimentações do plano, por meio de bases que são colocadas no seu interior (Figura 4). A base caleidoscópica é uma região que contém em seu interior segmentos apropriados, que permite a visualização, nos 
caleidoscópios, de pavimentações do plano. A construção dessas bases envolve o estudo de diversos conceitos geométricos, possibilitando o desenvolvimento de um trabalho diversificado no ensino de geometria.
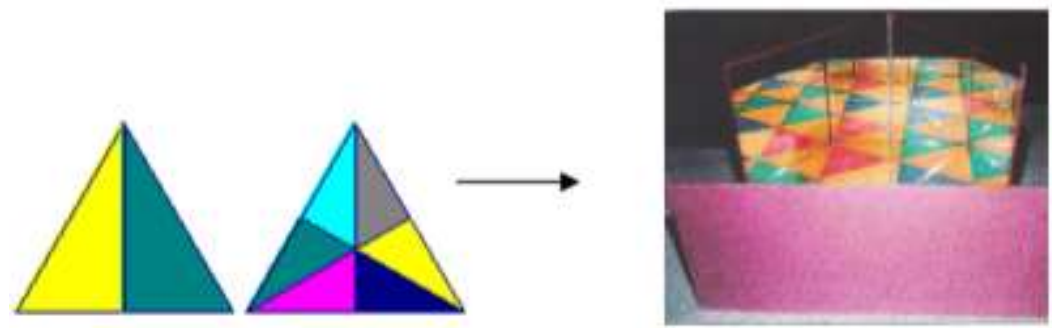

Figura 4 - Bases caleidoscópicas que permitem a visualização de pavimentação por triângulos equiláteros

Fonte: (SANTOS, 2006)

Murari (1999) apresenta três métodos para a determinação de bases caleidoscópicas², objetivando a visualização de pavimentações regulares, por meio da exploração de simetrias e construções geométricas. Ele propõe um trabalho voltado ao ensino de geometria partindo da investigação para a obtenção das bases. No estudo com os professores, focamos na obtenção de algumas delas.

\subsection{Tetraminós}

Os poliminós são obtidos pela conexão de quadrados congruentes (monominós) com um lado em comum. Barbosa (2005) explica que, talvez, o mais antigo problema envolvendo os poliminós seja o apresentado por Henry Ernest Dudeney, em 1907. Tal problema consistia no recobrimento de um tabuleiro quadrado 8x8 com poliminós. Os poliminós foram estudados por Salomon W. Golomb, em 1953, e amplamente divulgados por Martin Gardner em diversos artigos e em seu livro Divertimentos Matemáticos, de 1967, conforme explica Barbosa (2005).

Existem sete tipos de tetraminós (poliminós obtidos pela conexão, lado a lado, de quatro quadrados congruentes). Designaremos cada um deles usando letras do alfabeto: L, L invertido, Z, Z invertido, O, T e I (Figura 5).
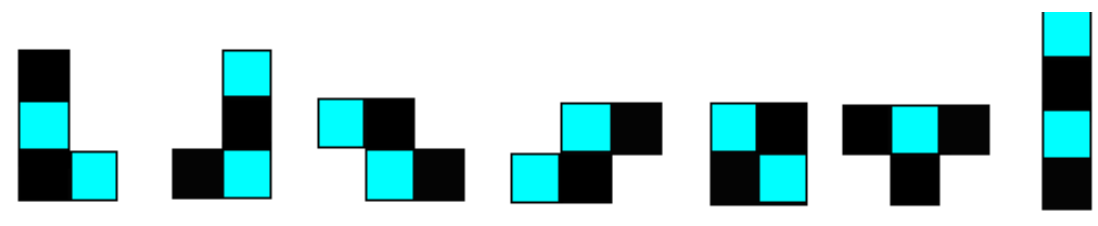

Figura 5 - Os sete tipos de tetraminós: L, L invertido, Z, Z invertido, O, T e I Fonte: (SANTOS, 2006)

\footnotetext{
${ }^{2}$ Informações mais detalhadas sobre o processo de determinação das bases caleidoscópicas podem ser obtidas nos estudos de Murari (1999), Almeida (2003), Martins (2003), Batistela (2005) e Gouvea (2005).
} 
Os tetraminós podem ser feitos em madeira, material emborrachado ou papel resistente. Barbosa (1993) sugere que, na construção das peças, faces opostas tenham cores diferentes, pois este cuidado permite que peças distintas sejam distinguidas durante a sua manipulação.

Diversas atividades envolvendo conceitos geométricos podem ser desenvolvidas utilizando-se os tetraminós. É interessante iniciar com o estudo exploratório sobre a composição dos tetraminós por quadradinhos unitários, o perímetro de cada peça e seus eixos de simetria.

Pode-se propor aos alunos diversos problemas de pavimentação parcial do plano, em especial de regiões retangulares. O papel quadriculado pode auxiliar na tarefa de representação das soluções, pois, em certos casos, pode haver mais de uma solução para o mesmo problema. O retângulo abaixo (Figura 6) representa a pavimentação de uma região retangular 4 x 6 por dois tetraminós T, dois Z, um L e um L invertido.

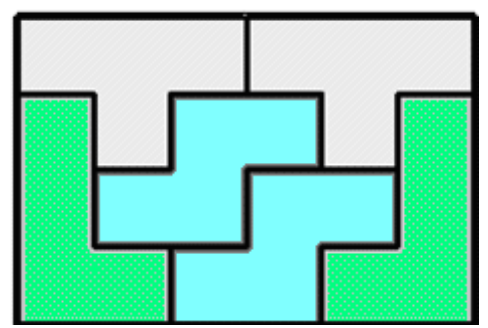

Figura 6 - Pavimentação de uma região retangular por tetraminós Fonte: (SANTOS, 2006)

Além do aspecto lúdico envolvido nas atividades com tetraminós, diversos conceitos podem ser abordados, como, por exemplo, na ampliação de uma das peças por meio de outras (Figura 7). Em atividades de ampliação, pode-se analisar as razões de semelhança entre os lados e as áreas das figuras envolvidas.
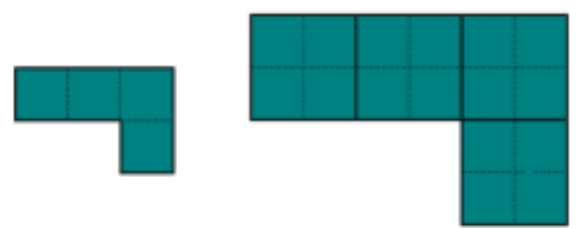

Figura 7 - Ampliação do tetraminó L invertido Fonte: (SANTOS, 2006)

Há muitas possibilidades de trabalho educacional com tetraminós e existem diversos trabalhos publicados em revistas e sites da internet envolvendo seu estudo.

\subsection{Pavimentação de Penrose}


O físico e matemático britânico Roger Penrose, aficionado por recreações matemáticas, percebeu que é possível pavimentar uma superfície plana de maneira não periódica, utilizando apenas dois quadriláteros irregulares denominados kite (pipa) e dart (dardo). Esses quadriláteros podem ser construídos a partir do pentágono regular (Figura 8).
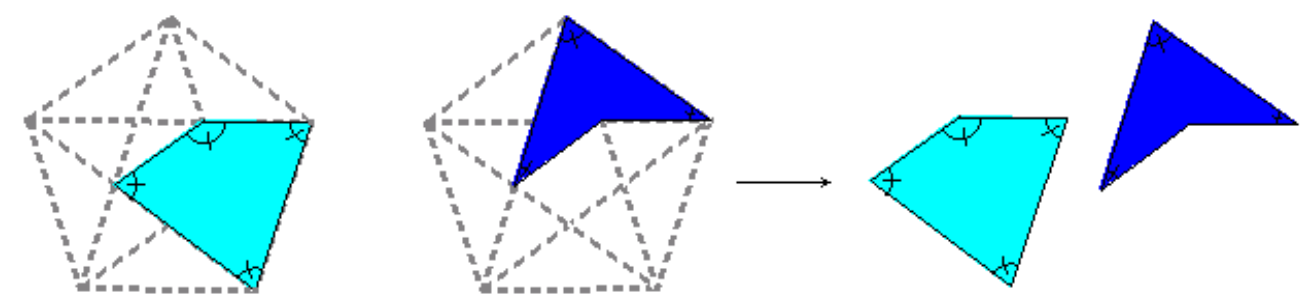

Figura 8 - Kite (pipa) e dart (dardo) gerados do pentágono regular Fonte: (SANTOS, 2006)

Combinando kites e o darts, podemos obter pavimentações periódicas (Figura 9) ou aperiódicas (Figura 10).

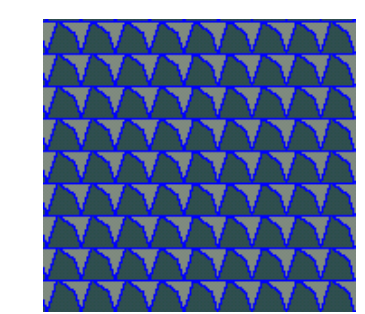

Figura 9 - Pavimentação periódica Fonte: (SANTOS, 2006)

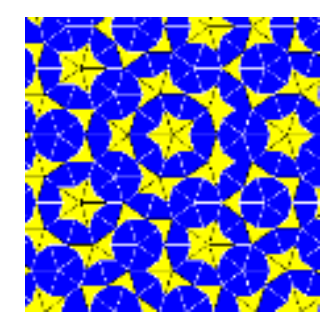

Figura 10 - Pavimentação aperiódica Fonte: (SANTOS, 2006)

As pavimentações de Penrose são aperiódicas, isto é, são aquelas que não podem ser obtidas pela translação de um padrão. Explicando melhor, se tivéssemos uma transparência de uma pavimentação de Penrose seria impossível movê-la em uma determinada direção de modo que ela coincidisse com a pavimentação original.

No estudo foram enfocadas as relações entre as pavimentações de Penrose e o número áureo, amplamente conhecido pelo seu caráter estético e íntima ligação com ideias artísticas.

Dos vários arranjos possíveis de se formar com kites e darts, ou combinando estas peças, apenas sete deles originam uma pavimentação aperiódica de Penrose (Figura 11).
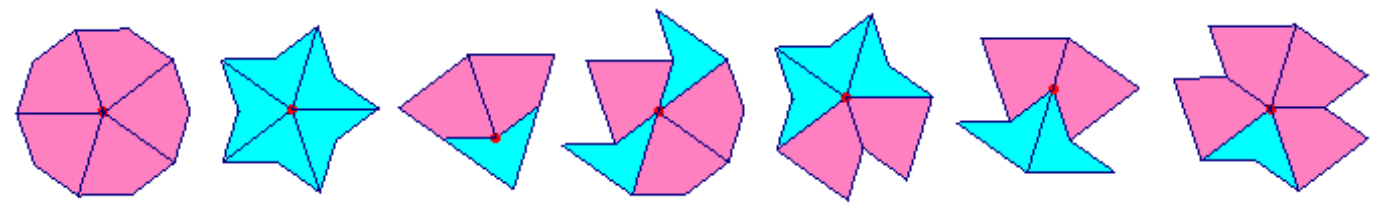

Figura 11 - Arranjos com kites e dartes de Penrose Fonte: (SANTOS, 2006)

Iniciando uma pavimentação pelo arranjo em forma de estrela (segundo arranjo) e mantendo uniforme a distribuição das peças em relação aos eixos de simetria do arranjo 
inicial, à medida que as peças são acrescentadas, mais a área pavimentada se aproxima da forma de um pentágono (GRÜNBAUM \& SHEPARD, 1989).

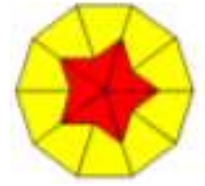

Figura 12 - Pavimentação de Penrose originada do arranjo em forma de sol Fonte: (SANTOS, 2006)

Outra curiosidade relacionada ao número áureo refere-se ao fato de que, em uma pavimentação de Penrose, quanto maior a região pavimentada, mais a razão entre a quantidade de kites e darts aproxima-se da razão áurea. Em uma pavimentação infinita, essa razão é exatamente a razão áurea (GRÜNBAUM \& SHEPARD, 1989).

Estes três tipos de pavimentações foram abordados no estudo realizado por Santos (2006) em um curso de formação continuada destinado a professores de Arte e Matemática da Educação Básica. O curso teve duração de oito encontros que foram gravados em vídeo, transcritos e analisados de modo qualitativo, em uma perspectiva fenomenológica (BICUDO, 2010).

A seguir, destacamos ações, diálogos e manifestações entre os professores ao permanecerem um com os outros, ao longo dos encontros havidos. Compreendemos que todos os oito encontros se entrelaçam, não sendo possível trazer apenas um como exemplo da prática formativa ocorrida. Assim, no desenrolar das considerações que apresentaremos a seguir, recortamos passagens de diálogos ocorridos e descreveremos aspectos importantes que fundamentam a análise efetuada.

\section{As perspectivas de olhar}

Ao nos voltarmos para o trabalho realizado, destaca-se o modo pelo qual cada professor se doou nos encontros, apresentando-se mediante linguagens que abrangem também aquela dita pela postura de seu corpo-próprio ${ }^{3}$, ou, dizendo em uma linguagem

\footnotetext{
${ }^{3}$ Modo como Husserl se refere ao Leib (corpo vivo), diferenciando de korper (corpo físico) conforme Bicudo (2010).
} 
fenomenológica, do seu ponto zero, de seu aqui onde estou, que estabelece a perspectiva pela qual visualiza o horizonte do seu aqui e agora (MERLEAU-PONTY, 1990; BICUDO, 2010).

O que isso quer dizer e como se revela no estudo de Santos (2006)? Ao se manifestar, cada participante ora destacava-se em sua singularidade ora se enredava aos outros. Era o professor especialista, de Matemática ou de Arte, mas, também, era o coletivo, formado por especialistas das duas disciplinas, que se fazia presente. A intersubjetividade estabelecida entre os sujeitos se mostrou na presentificação de cada um, tendo como cossujeitos o outro, de modo que sempre se está junto com na realização das ações.

Os significados destacados e analisados no estudo se explicitaram nas trocas, estranhamentos, expectativas, consensos e discordâncias ocorridos, relacionados à característica interdisciplinar dos encontros e aos direcionamentos que se deram junto ao estudo das pavimentações no ensino de geometria. Cada um percebe sentidos e expressa significados nos vários perfis pelos quais certo assunto pode ser nova e novamente visado. A atitude de abertura ao outro possibilita que esses sentidos (re)surjam, evidenciando a complexidade do tema tratado, a expressão do corpo próprio e a intersubjetividade estabelecida na realidade vivenciada.

Aspectos matemáticos e artísticos da geometria das pavimentações emergiram na experiência vivida no contexto dos encontros, expondo distintas formas de conceber e abordar as atividades propostas. Destacaram-se: a formalização matemática; as possibilidades de aplicação das atividades em sala de aula face às possibilidades dos alunos; os direcionamentos para a criatividade e exploração da arte na busca e representação das soluções. Destacamos aqui os seguintes diálogos entre os professores, extraídos de Santos (2006):

"há uma regra pra descobrir quando um arranjo pavimenta ou não o plano?" (M7, C16 "daria algumas dicas, mas deixaria que o aluno criasse. Surgem muitos trabalhos maravilhosos, independente, muitas vezes, da intervenção do professor" (A10, C25)

"tem como provar (M5, C39)

"não é pra reforçar as linhas da base, né, senão os triângulos ficam divididos" (A9, C23

"era dada pelo professor de educação artística. Era melhor" (M4, C1)

(Transcrição, Santos, 2006).

O rigor nas respostas, buscado por todos, e o caráter artístico das soluções se constituíram ao estar com o outro e partilhar concepções e ações pedagógicas. Isso levou os professores a analisarem possibilidades de agir na prática escolar, de forma integrada, porém com ações bem definidas, onde fica explicito, de modo contundente, que cada disciplina faz $a$ sua parte. Esses diálogos destacam essa separação nas ações: 


\begin{abstract}
"é um trabalho que o professor pode fazer um trabalho de integração. Elas o desenho [aponta para as professoras de arte] e a gente a geometria. Deve haver essa integração" (M7, C18) Quando tinha desenho geométrico elas [aponta para as professoras de arte] ensinavam e a gente o cálculo. A gente não tem mais. A gente trabalhava construção em desenho e cálculo em matemática. Agora não" (M9, C18)

"esse negócio de número é pra professor de matemática" (A3, C10)

(Transcrição, Santos, 2006).
\end{abstract}

Essa distinção ganhou destaque em meio ao estranhamento motivado pelo excesso de ênfase, em alguns casos, no conhecimento matemático. As professoras de Arte expressaram seu desapontamento entre o esperado e o encontrado em certas atividades propostas, o que evidenciou as dificuldades e despreparo do pesquisador-educador matemático para abordar a lógica das duas disciplinas, fazendo com que a dominância de uma das áreas, nesse caso a Matemática, se destacasse.

"Achei a atividade do caleidoscópio legal. Tudo no visual vai dar pra gente usar. Mas quando chegou esse negócio de contas...” (A3, C10)

"Não é que é o problema. Não é interessante. Nós não vamos usar, não é interessante pra gente" (A3, C10)

"Fala aqui: são mosaicos. E no mosaico pode ter espaço" (A8-C10)

(Transcrição, Santos, 2006).

Isso indica que a fase de elaboração de uma proposta envolvendo diferentes disciplinas deve ser muito bem planejada, com foco nas áreas envolvidas, de modo que uma delas não se imponha, a fim de que as especificidades de cada uma não se tornem um obstáculo para as interações possíveis. Entende-se que um trabalho que visa transcender os limites impostos pelas disciplinas exige uma

$$
\begin{aligned}
& \text { postura de reconhecimento onde não há espaço e tempos culturais privilegiados que } \\
& \text { permitam julgar e hierarquizar - como mais corretos ou mais verdadeiros - } \\
& \text { complexos de explicação e convivência com a realidade que nos cerca. } \\
& \text { (D’AMBROSIO, 1997). }
\end{aligned}
$$

No estudo, os diálogos evidenciaram a busca de compreensão das perspectivas de olhar do outro. Assim, para além da formação específica, a prática docente dos envolvidos foi reavivada em vários momentos dos encontros, ao discutirem, por exemplo, formas de implementar as atividades em suas turmas.

"E agora, também, essa formação das aulas práticas, esse trabalho que a gente tá fazendo. Porque nos cursos a gente tem muita teoria, muita coisa bonita. Eu acho que não tem a prática" (A3-C7)

"aquela explicação me deu um insight" (A3-C10)

"eu achei importante, como professora de arte, porque eu tirei do bidimensional, que é muito difícil do aluno visualizar, e trouxe pro tridimensional, usando objetos. E ficou muito mais fácil de explicar. (A3-C7

(Transcrição, Santos, 2006). 
Apesar de as discussões ocorridas quanto ao trabalho conjunto não transcenderem a mera análise das ações e consequências envolvidas em práticas interdisciplinares, a reflexão sobre sua possibilidade floresceu. A abertura dos professores para envolver-se com colegas de áreas distintas revelou sujeitos abertos à interdisciplinaridade buscando formas de ser no mundo com.

Destacou-se, entre os professores, o desejo de conhecer e inteirar-se dos temas e assuntos próprios à outra área de conhecimento. E, ao compartilharem a prática pedagógica específica de sua disciplina, ocorreu um apropriar-se das formas de conceber do outro, que possibilitou a reorganização do olhar e a busca por ações. Explicitou-se que o movimento de visar algo que se mostra vai além das percepções individuais: as ideias geométricas, foco do estudo, não são meramente elaborações subjetivas, pois a experiência vivida permite que o sujeito (re)organize compreensões que trazem o percebido e o seu entorno, tornando possível a expressão do compreendido aos cossujeitos. O compartilhar de experiências estabelecido nos encontros mostrou-se nas indagações, na proposta de atividades e de problemas, na atenção à discussão estabelecida etc.

Assim, no ambiente constituído pela intersubjetividade, em que a subjetividade se assume no seu ser-com-o-outro, cada professor percebe a si próprio e aos demais, expondo-se e dando-se conta dos companheiros. Nas vivências dos encontros, evidenciou-se a importância das trocas entre as disciplinas, das interações entre modos de conceber determinados assuntos e da disposição para abrir-se à compreensão do modo de olhar do outro, impulsionando a produção de conhecimento.

O ser-com-o-outro se concretiza no movimento simultâneo de subjetividade e intersubjetividade em direção a uma objetividade, movimento ilustrado por Martins (1992) da seguinte forma:

\footnotetext{
Duas pessoas A e B, ao observarem uma paisagem do mundo, participam de valores presentes nesse mesmo mundo onde as duas perspectivas convergem. A consciência de A e a consciência de B estão assim em comunicação. A percepção do mundo por A não significa, porém, que ele esteja observando a mesma coisa que $\mathrm{B}$ quando percebe o mundo. Ambos estão chegando a uma forma pré-pessoal de consciência, onde a comunicação não apresenta problemas, uma vez que a definição de consciência refere-se ao significado ou à realidade de $\mathrm{A}$ e de B. É a intersubjetividade entre A e B que permitirá uma participação de verdades entre A e B, ou seja, a verdade será construída a partir da intersubjetividade de A e de B.
}

Ver o ensino e a apreendizagem por vários olhares contribuiu para a compreensão da complexidade do ambiente escolar e da formação dos envolvidos.

\section{A formação de professores e o trabalho coletivo}


A integração das vivências havidas nos encontros com as experiências da prática docente dos professores revelou-se em diversos momentos: ao trazerem à presença, na lembrança, seus alunos nas discussões das atividades, ao transporem para os encontros suas experiências de sala de aula e vice-versa, ao exporem suas expectativas com relação aos materiais trabalhados, enfim, ao revelarem sua imersão na cultura escolar.

Explicitaram-se expectativas e anseios com relação ao curso e às ações em sala de aula, como desejo de ampliar o conhecimento e melhorar a prática no ensino de geometria, o que mostra a intencionalidade dos professores dirigida para a atualização de suas compreensões sobre o tema. O assunto em foco foi um polo de convergências das intencionalidades dos sujeitos da pesquisa, impulsionando o processo de abertura para a realização de reflexões coletivas sobre a geometria, as atividades, as possibilidades de ações e as dificuldades que se colocam para prática docente.

O outro, o aluno, mesmo não estando com os professores no aqui do curso, trouxe sua contribuição para os diálogos quanto à ação educativa: a todo momento são mencionados nos diálogos havidos, considerando-se suas características e ações próprias. Dessa forma, passado e futuro se interpenetram na experiência vivenciada, revelando modos de se estar no tempo e espaço: aqui (nos encontros) e ali (na sala de aula com os alunos). Ao retomarem e reorganizarem suas experiências educativas em sala de aula, eles parecem vislumbrar um horizonte que os impele a avançar.

"Na manipulação de objeto ele vai entender melhor o conceito. Fica muito mais fácil, ele vai entender muito melhor o conceito" (A3-C7)

"hoje na oitava série... Eu acho que se iniciar com eles já na quinta vai criando..." (M9-C18)

"depende do que você tá trabalhando, né, da série..." (A10-M21)

"mas, os mais bagunceiros é que são bons nisso" (M5-C33)

(Transcrição, Santos, 2006).

Os professores refletem sobre a importância que os assuntos, atividades e materiais trabalhados nos encontros poderiam ter para a sua disciplina, discutem a aprendizagem dos alunos e analisam ações pedagógicas. Surgem significados relacionados a um trabalho coletivo no ambiente escola, indicando a disposição necessária para que ele se efetive, denunciando sua natureza social e a necessidade de uma postura de compromisso dos envolvidos - professores, coordenadores e direção.

"o número de aluno na sala, o material que você consegue.

"mas não é. Nós também temos medo de fazer coisa diferente" (M6-C18)

(Transcrição, Santos, 2006).

Um projeto elaborado em com-junto pressupõe a existência de projetos pessoais, de histórias de vida, e traz consigo o sentimento de pertença ao mundo que nos coloca junto aos 
demais, pois, estando situado e envolvido, "eu nunca estou fechado num mundo como um objeto numa caixa. Minha liberdade, o poder fundamental de que gozo, por ser o sujeito de todas as minhas experiências, não diverge de minha inserção no mundo". (MARTINS, 1992, p. 53)

Mas, a mudança na prática educativa é complexa e muitos aspectos se entrelaçam na realidade vivenciada, trazendo dificuldades para que ela ocorra. Dentre esses aspectos, podemos destacar, como exemplo: a proposta pedagógica da escola, os objetivos do ensino de determinada disciplina, o controle da sala de aula, a avaliação.

Modificações profundas no sistema de concepções e renovação das ações não são simples e só se verificam perante abalos, geradores de desequilíbrios no âmbito de vivências pessoais (HIRATSUKA, 2003). Considerando que as mudanças envolvem aspectos específicos aos professores e ao ambiente escolar, tem-se que a formação não se limita à participação em cursos e capacitações. Ela carrega significados complexos:

\begin{abstract}
formação designa o processo de devir, em que o contorno da imagem, que persegue o modelo, se realiza. Mas é mais que isso. Esse processo, porém, não se efetua de modo a atender a uma finalidade técnica a ela externa, mas brota do processo interno de constituição e de formação, permanecendo em constante evolução e aperfeiçoamentos. (BICUDO, 2003, p. 28)
\end{abstract}

Ou seja, a formação diz da forma e da ação. Forma ligada à imagem do papel social do professor. Ação que, ao agir, realizar, se coloca em movimento pela propulsão da intencionalidade da pessoa, na condição existencial de ela estar voltada para sua prática em sala de aula, a caminho de ações diversificadas em sua atividade docente.

É certo que, sem o mundo contextual, as ações não se materializam. Portanto, no ensino de geometria é preciso considerar o contexto da realidade escolar do professor e do aluno. Mas, é certo, também, que, sem uma forma prévia do papel a ser desempenhado, as ações se perdem à procura de delineamentos. A forma/ação é o movimento de fazer. Na ação a forma vai se constituindo. Contudo, é uma forma que carrega consigo a tradição das práticas histórico e socialmente efetuadas e também a marca do momento presente, nas ações de pessoas que estão intencionalmente voltadas a um mesmo fim.

A intencionalidade de cada professor o mantém atento às falas e manifestações que se dão no decorrer dos encontros, possibilitando: o compartilhamento dos materiais utilizados em sala de aula e dos conhecimentos próprios de cada disciplina; a exposição de experiências em sala de aula e de formas de ensinar os assuntos tratados; a discussão de enunciados e de suas compreensões; o auxílio ao colega em suas dificuldades. 
Assim, o ambiente sustentado pela intersubjetividade se mostra como solo da atividade interdisciplinar e possibilita que cada um vá abrindo possibilidades, pois "o homem não é por natureza aquilo que está destinado a ser e, como ser de possibilidades, necessita construir-se na sua humanidade, o que se realiza através do ato de educar propriamente dito" (MARTINS, 1992).

É importante ressaltar outros aspectos que transcendem às expectativas quanto ao trabalho coletivo exposta pelos professores durante o curso. Destaca-se a importância dos ambientes educacionais que primam por atividades interdisciplinares em cursos de formação e na prática pedagógica. $\mathrm{O}$ trabalho solitário, comum na prática da maioria dos professores, seja pela falta de tempo ou de condições, leva a uma inércia e consequente desânimo que faz com que muitas ações planejadas não se efetivem. Como consideram Borba e Penteado (2003, p.70), “o trabalho individual estimula a estagnação. É o pensar e agir coletivo que poderão impulsionar e manter o professor numa zona de risco de forma que ele possa usufruir do seu potencial de desenvolvimento".

Propostas curriculares de ensino, como os PCN (BRASIL, 1998), por exemplo, indicam que trabalhos em conjunto sejam realizados pelos professores nas escolas. Entretanto, quando o que se busca é um trabalho que transcenda a mera exposição de conceitos e que possibilite um enfoque interdisciplinar, torna-se imprescindível que se disponha de recursos e conteúdos diversificados e, mais do que isso, é preciso que a ênfase recaia nas ações e na construção conjunta entre os sujeitos da ação, em um processo que valorize a percepção e a expressão dos sentidos e significados próprias da prática pedagógica dos envolvidos.

As diferentes realidades escolares que os professores, em geral, vivenciam em sua (longa) jornada de trabalho também devem ser consideradas ao se propor projetos para serem realizados entre diferentes disciplinas. Torna-se importante considerar as características do ambiente de trabalho dos professores e as políticas educacionais envolvidas. Compreender a realidade dos que vivem o dia a dia da escola também é importante para a transformação da realidade, em direção a um trabalho voltado para ações solidárias, planejadas pela equipe escolar, que incidam na qualidade do sistema educativo. É significativo considerar a vivência da prática de ensino dos envolvidos, em análises reflexivas realizadas em grupo, sobre o que já foi realizado e sobre as possibilidades que se abrem, permitindo visualizar caminhos a serem trilhados.

\section{0 trabalho interdisciplinar em Educação Matemática}


Pesquisas e estudos recentes indicam que a Matemática está sendo chamada a engajarse na crescente preocupação com a formação integral do aluno, visando formá-lo como cidadão (TOMAZ \& DAVID, 2008). Destaca-se a necessidade de tratar o ensino da disciplina, levando-se em conta a complexidade do contexto social e a abrangência da visão interdisciplinar.

Por outro lado, diversos são os desafios e necessidades colocados, tanto ao pesquisador em suas investigações quanto ao professor em sua prática.

As análises das interações entre os professores de Matemática e Arte evidenciaram a importância de estar-se disposto a abrir-se ao outro, reordenando referências quando for o caso. Dessa forma, o trabalho interdisciplinar, construído no movimento de intersubjetividade e diálogo, caminha na perspectiva da compreensão do trabalho efetuado por professores e alunos em distintas disciplinas, mas que, por estarem juntos, vão se abrindo a horizontes de ideias nucleares que estão presentes na constituição do conhecimento de ambas as disciplinas envolvidas.

Os encontros, desencontros, articulações e distanciamentos que se dão tanto entre as pessoas que vivenciam a experiência de trabalhar com professores de disciplinas diferentes, como no diálogo científico em que se expõem compreendendo o que o outro diz, destacaram a importância de se reconhecer como legítimas as diversas abordagens que podem emergir em uma experiência interdisciplinar.

A Educação Matemática, como área que se caracteriza pelo seu objeto interdisciplinar, há que estar atenta às áreas de conhecimento que constituem suas interfaces. Do ponto de vista da lógica do conhecimento das diferentes disciplinas, o educador matemático deve entender a lógica de sua disciplina, a Matemática, e também daquela com a qual está trabalhando. O mesmo movimento há que ser realizado por parte do professor da outra disciplina. Nesse movimento há uma busca comum que solicita que seja trilhado um caminho de acertos e desacertos, de paciência e de respeito ao outro.

Algumas questões lançadas por Santos (2006) ainda se fazem atuais e podem contribuir com aqueles que se proponham a realizar trabalhos interdisciplinares voltados para o ensino e a aprendizagem. Entendemos que na elaboração da própria proposta de trabalho, as pessoas envolvidas deveriam se perguntar: quais são as necessidades humanas, materiais e metodológicas que devem ser consideradas para a realização de uma proposta interdisciplinar? Como lidar com situações inesperadas, como aquelas que envolvem a especificidade de cada uma das áreas? Como um grupo de pesquisa interdisciplinar pode 
contribuir com compreensões e ações interdisciplinares? Quais os reflexos das vivências em estudos interdisciplinares tanto na prática pedagógica como nas concepções dos envolvidos?

Não concluindo, mas abrindo novas indagações e destaques que se apresentam, entendemos que retomadas do tema e de práticas pedagógica interdisciplinares possibilitam revivificações de experiências e de intuições, de modo que complexidades da produção do conhecimento se mostrem e possam ser reelaboradas.

\section{Referências}

ALMEIDA, S. T. Um estudo de pavimentação do plano utilizando caleidoscópios e o software Cabri Gèomètre II. 2003. 147 p. Dissertação (Mestrado em Educação Matemática) - Instituto de Geociências e Ciências Exatas, Universidade Estadual Paulista, Rio Claro, 2003.

ARANHA, C. S. G. A arte visual na sala de aula. 1981. Tese (Doutorado em Educação Matemática)Pontifícia Universidade Católica, São Paulo, 1981.

BARBOSA, R. M. Poliminós. Catanduva: IMES, 2005.

BARBOSA, R. M. Descobrindo padrões em mosaicos. São Paulo: Atual, 1993.

BATISTELA, R. F. Um Kit de Espelhos Planos para o Ensino de Geometria. 2005. 134 p. Dissertação (Mestrado em Educação Matemática) - Instituto de Geociências e Ciências Exatas, Universidade Estadual Paulista, Rio Claro, 2005.

BRASIL. Secretaria de Educação Fundamental. Parâmetros Curriculares Nacionais: Matemática. Brasília: MEC/ SEF, 1998.

BUSKE, N. Uma Contribuição para o Ensino de Geometria Utilizando Origami e Caleidoscópio. 2007. 200 p. Dissertação (Mestrado em Educação Matemática) - Instituto de Geociências e Ciências Exatas, Universidade Estadual Paulista, Rio Claro, 2007.

BICUDO, M. A. V. A constituição do objeto pelo sujeito. In TOURINHO, C. D. C. (Org.). Temas em fenomenologia. Rio de Janeiro: Booklink, 2012.

. Filosofia da Educação Matemática: fenomenologia, concepções, possibilidades didáticopedagógicas. 1 ed. São Paulo: Editora UNESP, 2010.

. Formação do professor: um olhar fenomenológico. In BICUDO, M. A. V. (Org.). Formação de professores: da incerteza a compreensão? São Paulo: Edusc, 2003.

BORBA, M. C; PENTEADO, M. G. Informática e educação matemática. São Paulo: Autêntica, 2003.

DAFFER, P. G. O; CLEMENS, R. S. Geometry: an investigative approach. Menlo Park: AddsonWesley. 1977.

D’AMBRÓSIO, U. Transdisciplinaridade. São Paulo: Palas Athena, 1997.

GOUVEA, F. R. Um Estudo de Fractais Geométricos Através de Caleidoscópios e Softwares de Geometria Dinâmica. 2005. 259 p. Dissertação (Mestrado em Educação Matemática) - Instituto de Geociências e Ciências Exatas, Universidade Estadual Paulista, Rio Claro, 2005. 
GRÜNBAUM, B.; SHEPHARD, G. C. Tilings and Patterns. New York: W. H. Freeman and Company, 1987.

HIRATSUKA, P. I. A vivência da experiência da mudança da prática de ensino de Matemática. 2003. 492 p. Tese (Doutorado em Educação Matemática) - Instituto de Geociências e Ciências Exatas, UNESP, Rio Claro. 2003.

HUSSERL, E. A Crise das Ciências Europeias e a Fenomenologia Transcendental : uma introdução à filosofia fenomenológica. Tradução de Diogo Falcao Ferrer. Rio de Janeiro: Forense Universitária, 2012.

MARTINS, J. Um enfoque fenomenológico do currículo: educação como poíesis. São Paulo: Cortez, 1992.

MARTINS, R. A. Ensino-aprendizagem de geometria: uma proposta fazendo uso de caleidoscópios, sólidos geométricos e softwares educacionais. 2003. 246 f. Dissertação (Mestrado em Educação Matemática) - Instituto de Geociências e Ciências Exatas, Universidade Estadual Paulista, Rio Claro, 2003.

MERLEAU-PONTY, M. O primado da percepção e suas consequências filosóficas. Tradução de Constança Marcondes César. Campinas: Papirus, 1990.

MURARI, C. Ensino-aprendizagem de geometria nas $7^{\text {a }}$ e $8^{\text {a }}$ séries via caleidoscópios. 1999. Tese (Doutorado em Educação Matemática) - Instituto de Geociências e Ciências Exatas, Universidade Estadual Paulista, Rio Claro, 1999.

NEVES P. R. V. O Uso de Caleidoscópios no Ensino de Grupos de Simetria e Transformações Geométricas. 2011. 146 p. Dissertação (Mestrado em Educação Matemática) - Instituto de Geociências e Ciências Exatas, Universidade Estadual Paulista, Rio Claro, 2011.

REIS, J. D. S. Geometria Esférica por meio de materiais manipuláveis. 2006.158 f. Dissertação (Mestrado em Educação Matemática) - Instituto de Geociências e Ciências Exatas, Universidade Estadual Paulista, Rio Claro, 2006.

SANTOS M. R. Pavimentações de Plano: um estudo com professores de matemática e arte. 2006. 177 f. Dissertação (Mestrado em Educação Matemática) - Instituto de Geociências e Ciências Exatas, Universidade Estadual Paulista, Rio Claro, 2006.

SANTOS, M. R; BATISTELA, R. F. O uso dos caleidoscópios em cursos de licenciatura em matemática: possibilidades investigativas. In: XI ENCONTRO NACIONAL DE EDUCAÇÃO MATEMÁTICA, Curitiba. Anais... Curitiba: UFPR, 2013, p. 1-12.

SILVA, V. C. Ensino de geometria através de ornamentos. 1997. Dissertação (Mestrado em Educação Matemática) - Instituto de Geociências e Ciências Exatas, Universidade Estadual Paulista, Rio Claro, 1997.

TOMAZ, V. S.; DAVID, M. M. M. S. Interdisciplinaridade e aprendizagem da Matemática em sala de aula. Belo Horizonte: Autêntica, 2008.

Submetido em Abril de 2015. Aprovado em Julho de 2015. 